\title{
Um Entre o Outro e Eu: do estranho e da alteridade na educação
}

Ana Paula Bellochio Thones'

Marcelo de Andrade Pereira'

'Universidade Federal de Santa Maria (UFSM), Santa Maria/RS - Brasil

RESUMO - Um Entre o Outro e Eu: do estranho e da alteridade na educação. Discorre sobre o conceito do estranho na arte, na antropologia e na psicanálise, a fim de analisar as injunções poético político pedagógicas do estranho no âmbito da educação. Toma como problemática a relação entre o eu e o outro na sociedade contemporânea, mais especificamente, na manifestação do estranho - o qual refere tanto um sentimento quanto uma representação - nos espaços formativos - supostamente familiares ou de familiarização. Trata, portanto, da alteridade, tomada como forma de visibilidade e relação do mesmo com o outro. O estudo propõe pensar o ensino como forma de estranhamento.

Palavras-chave: Estranho. Psicanálise. Alteridade. Educação.

ABSTRACT - A Gap Between the Other and Me: of the uncanny and alterity in education. Discusses the concept of the uncanny in the arts, anthropology and psychoanalysys in order to analyze the poetical and political injunctions of the uncanny in education. It considers the problem of the relationship between self and the other in contemporary society, more specifically, in the manifestation of the uncanny - wich may refer both to a feeling and to a form of representation - in educational spaces - supposedly familiar or for familiarization. The theme, therefore, is alterity, taken as a form of visibility and relationship with the other. The study proposes to consider teaching as an expression of the uncanny.

Keywords: Uncanny. Psychoanalysis. Alterity. Education.

Educação \& Realidade, Porto Alegre, v. 38, n. 2, p. 501-520, abr./jun. 2013. 


\section{Um Descomeço}

Este estudo ocupa-se da abordagem e da construção do estatuto do estranho [e de sua implicação] no contexto educativo. Dito de outro modo, essa investigação se propõe a discorrer sobre o sentimento do estranho, como também de sua representação no âmbito educacional, inferindo que tal noção permita pensar o problema da alteridade na educação - a partir de um viés estético - dimensão que se supõe aqui criptografada no estabelecimento do laço social. Isso implica, como veremos, refletir sobre termos correlatos ao estranho, tais como duplo, angústia, repetição, Outro ${ }^{1}$. A tarefa apresenta-se como de difícil realização - contudo, não impossível - na medida em que o conceito apresenta-se como pendular, relativo e relacional; oscilando entre, de um lado, um sentimento, um afeto, de outro, da representação do eu com relação ao outro. Aqui, o estranho constitui um território minado, ou melhor, um desterritório.

A rigor, discutir o estranho significa discorrer sobre uma espécie de não saber, de sua experiência propriamente dita. Para saber é preciso, primeiro, não saber. O estranho apresenta-se, pois, como um objeto que é capaz de brincar com a condição do sujeito pesquisador, que o desloca e que o faz por vezes, por muitas vezes, o seu objeto. Esse objeto constitui uma categoria que não se deixa categorizar, que é estranha às suas classificações, refratária à posse. O intento desse estudo será, portanto, de delinear, de dar um curso a um fluxo afetivo, o qual pode se constituir ora acidentado, ora não devidamente formalizado. O estranho consiste, com efeito, por efeito e invariavelmente, em um risco.

Como veremos, muitas são as definições e as relações que se fazem em torno dessa (paradoxal) categoria - compreendida como o modo pelo qual se pergunta por alguma coisa, no caso, sobre um afeto e uma representação. Supomos, assim, que a apreciação sobre a produção do estranho entre diferentes campos do saber e pela letra de diversos autores permita uma maior aproximação e vislumbre deste fenômeno no cenário educativo, no qual se encena uma série de conflitos decorrentes da relação do eu com o outro, de uma hipotética (im)possibilidade de reconhecimento do Outro pelo eu. É dentro contexto que se pode também entrever uma prática formativa que se oriente pela destruição de certezas naturalizadas historicamente.

Para levar a termo o intento, o estudo parte num primeiro momento da tentativa de conceituação do estranho - o qual implica deslindar suas significações linguísticas, psicanalíticas -, para então, num segundo momento enlaçá-lo ao problema da alteridade. Um terceiro momento argumentativo concerne à proposição de uma pedagogia estranha - por assim dizer, antipedagógica, antipedagogizante. Tal proposição encontra, ademais, eco nas inúmeras formulações teóricas existentes nos domínios da psicanálise, da arte, da filosofia, como também da antropologia. 


\section{O Estranho: um problema de definição}

No início do século XX, Sigmund Freud (1969) interessou-se pelo tema do "estranho". Formulou uma hipótese de que a pesquisa pelo estranho poderia lhe trazer questões concernentes às suas descobertas analíticas e à teoria da psicanálise. Sua curiosidade se refere, sobretudo, a ser o estranho um ramo negligenciado da estética, já que o enfoque que normalmente é dado por essa teoria era, pelo menos em seu tempo, o estudo da beleza.

Pode-se dizer, portanto, que, assim como a religião, a sexualidade e o dinheiro, a temática do estranho foi captada por Freud como um assunto gerador de polêmica e de constrangimento, o qual a sociedade, em geral, evitava e ainda evita abordar. Como um psicanalista ciente da importância de trazer à tona elementos reprimidos, Freud (1969) procurou em seu texto intitulado Das Umheimlich, de 1919, aprofundar-se na temática do estranho, com a ajuda dos alicerces literários e analíticos de que dispunha.

Freud encontrou na literatura alemã um indício anterior a respeito do estranho. Trata-se de um artigo de Jentsch, de 1906, o qual trazia a ideia de que o fator essencial na origem do sentimento de estranheza seria a incerteza intelectual. Tal incerteza poderia se expressar em relação ao ambiente, ou seja, quanto mais orientado no ambiente estivesse um sujeito, menos ocorreria a ele a impressão de algo estranho, e vice-versa. Freud buscou, ainda, o significado da palavra em sua língua materna. Unheimlich, estranho em alemão, se refere a algo assustador e ao mesmo tempo familiar. Tais notações, como veremos, são a priori insuficientes ao tentarem definir o estranho, sobretudo quando tomadas isoladamente.

A fim de não se limitar ao significado alemão e encontrar definições que poderiam levá-lo ao aprofundamento de sua pesquisa, Freud buscou, com ajuda de Theodor Reik, o conceito de estranho em outras línguas. Essa necessidade de levantar as diferentes significações do estranho se deve, não obstante, ao fato de que para Freud a própria língua seria também uma língua estrangeira.

A investigação de Royle (2003) nos convida, com efeito, a pensar quem é o sujeito na frase de Freud, e em qual língua seria correto definir o estatuto do estranho. Royle parte da intuição de que Freud já teria dito de antemão que não importa qual seja a língua que um pesquisador estude o estranho, ela sempre será estrangeira.

Nesse sentido, tem-se o termo unheimlich (Freud, 1969) que, em latim significa o locus suspectus, o qual refere um lugar estranho; na língua grega, o estranho remete ao estrangeiro; ao passo que na língua francesa, o estranho aparece sob a forma do inquietante, do sinistro, lúgubre, de algo como não estar à vontade, de não se sentir cômodo, de estar ou se sentir constrangido; na língua espanhola, a palavra estranho aparece como sospechosa, de mal auguero, lúgubre, siniestra; no árabe 
Um Entre o Outro e Eu

e hebreu, estranho significa demoníaco, horrível; e na língua inglesa, tem-se o uncanny (que tem relação com sagaz) unconfortable, uneasy, gloomy (ligado à melancolia, ao desconforto), haunted (assombrado) repulsive (repulsivo).

Com essas definições, é possível tecer novas relações com a palavra alemã unheimlich. Além do assustador e familiar, podemos inferir os termos lugar estranho (que pode se articular à ideia de Jentsch de uma pessoa desorientada no ambiente) estrangeiro (que pode dar a idéia de alguém vindo de outro lugar), sinistro (que se relaciona ao lado esquerdo, em espanhol), lúgubre (relacionado à fúnebre, à morte), suspeito (que não se pode confiar), inquietante (que pode gerar ansiedade), sagaz (astuto, clarividente).

No oposto alemão da palavra unheimlich (estranho), ou seja, heimlich, Freud encontra duas curiosas definições, retiradas do Wortebuch der Deutschen Sprache, um dicionário de 1860, escrito por Daniel Sanders. Na primeira definição, Freud encontra o heimlich como familiar, doméstico, íntimo, amistoso, obsoleto, alegre, disposto, sendo aplicado também para o tempo. Já na segunda definição, o termo aduz ao oculto, ao íntimo, como algo escondido dos outros, encontro, caso de amor, lugar ou comportamento estranho. Assim, temos em Heimlich uma palavra ambígua que pertence a dois conjuntos de idéias diferentes: de um lado, familiar e agradável, de outro, o que é íntimo e está oculto. No dicionário de Grimm (1877), Freud encontra o Heimlich como o ligeiramente diferente, livre de fantasmas, familiar, afastado dos olhos de estranhos, secreto, místico, alegórico, e, por fim, inconsciente.

$\mathrm{O}$ verbete unheimlich refere, em contrapartida, a algo misterioso, sobrenatural, que desperta horrível temor - significações essas que aparecem no mesmo dicionário de Sanders, consultado por Freud. Para Freud, recobrando as palavras de Schelling, o estranho diz respeito a tudo aquilo que deveria permanecer secreto, oculto, mas veio à luz (Freud, 1969). Com toda essa diversidade de definições e diferenciações entre os termos opostos, Freud chega ao entendimento de que Unheimlich é uma subespécie de Heimlich.

Outra interessante definição do unheimlich se refere a mal-estar. Tal significação se deve, tal como nos indica Pereira (2007), à etimologia de heim, palavra provinda da raiz indoeuropéia kei (estar deitado), que passou também ao gótico haim (aldeia), no antigo alemão, que significa casa, morada, pátria. Pereira (2007) lembra, ainda, que este mesmo substantivo some entre os séculos XVI e XVIII, retornando ao uso na língua inglesa como home (lar, casa). A significação de "mal-estar" surge, assim, de forma mais clara, apenas a partir do século XVIII (Pereira, 2007, p. 10-11).

Além das curiosas descobertas realizadas em sua pesquisa acerca do conceito do estranho, Freud buscou seu significado em eventos e fenômenos que causam estranheza. Com isso, ele constatou que entre os exemplos de coisas assustadoras existe uma classe em que o elemen- 
to que amedronta pode mostrar-se como algo reprimido que retorna, sendo essa classe o estranho, independentemente se o elemento estranho era originalmente assustador ou não. Assim, o estranho não é nada novo ou alheio ao sujeito, mas algo que é familiar e há muito nele instalado, sendo que somente teria se alienado de sua consciência por uma operação de repressão.

Seja como for, Freud também encontrou algumas ressalvas em sua pesquisa. Descobriu que tudo o que podemos tomar como estranho é reprimido, mas nem tudo o que é reprimido é estranho, somente aquilo que podemos experimentar como familiar ou assustador (Freud, 1969). Desse modo, mesmo que Freud aponte a angústia de castração como fonte de estranheza, a qual é essencialmente ligada à repressão, ele reconhece a existência de um mais além a ser vislumbrado, deixando em aberto suas próprias constatações. Saceanu (2005) nos lembra a esse respeito que é exatamente dessa maneira que Freud permite que seu ensaio fique marcado de uma certa indecisão, o qual busca ao mesmo tempo preservar a univocidade de seu conceito e admitir o jogo, o encadeamento infinito de substitutos. Nesse sentido, tal afirmação pode explicar porque em Freud o estranho opere - e se defina enquanto tal - como, ora reflexo do funcionamento neurótico do recalque, ora narrativa ou experiência dos limites do eu (Martini; Junior, 2010, p. 371).

A resposta encontrada por Freud para dar conta de seus questionamentos a respeito do estranho é admitir a existência de outros elementos além dos estabelecidos que fazem surgir tal sensação, necessitando para isso de uma investigação estética. Reconhece, porém, que esses outros elementos aparecem, como vimos, no campo da ficção. Faz-se, então, uma distinção entre o estranho experimentado no campo da realidade (referente a algo familiar que fora reprimido) e o estranho que lemos ou visualizamos no campo da ficção (que pode se remeter a um conteúdo familiar e reprimido e muito além disso). Assim, em relação ao campo da realidade, o sujeito pode ou não sentir o estranho ao se deparar com um evento que tem condições para fazê-lo surgir. O duplo é um termo que se enquadra nessa consideração estética de Freud. Se, como vimos, o unheimlich é, para Freud, uma espécie de heimlich, isso quer dizer que o estranho mantém íntima relação com o que é próprio, aparecendo, assim, como o duplo do mesmo.

\section{O Duplo e a Angústia de Ser Outro, Mesmo}

Como se pode constatar, o duplo constitui no ensaio freudiano sobre o estranho um aspecto de fundamental importância. Amparado pelas ideias de Otto Rank - psicanalista que em 1914 havia publicado um estudo sobre o duplo - Freud infere que tal noção designa um componente psíquico. Em Rank (1976), o duplo consiste em uma segurança contra a destruição do eu e uma negação do poder da morte. Sua concepção está, com efeito, arraigada na produção literária de sua época - no que tange àquela que gira em torno de tal tema. Rank toma tal ma-

Educação \& Realidade, Porto Alegre, v. 38, n. 2, p. 501-520, abr./jun. 2013. 505

Disponível em: <http://www.ufrgs.br/edu_realidade> 
Um Entre o Outro e Eu

terial como marca indiciária da condição do próprio autor, na medida em que compreende que tais ficções incorrem numa espécie de deslinde autobiográfico, de reduplicação do eu do autor. Isto é, para Rank, existe uma correlação direta do escrito com o psiquismo do escritor. O duplo, nesse sentido, ocuparia o espaço da sombra, dos fantasmas que retornam, dos reflexos perdidos, de sujeitos que na ficção procurariam persistir à morte.

Pautado por essa definição Freud elaborará, tal como nos lembra Ana Gaspar (2011), uma noção de duplo como recalque, ambivalência e dinamismo psíquico. Para Freud (1969), o duplo teria relação com o narcisismo primário, tempo do amor próprio ilimitado, em que a criança precisa do investimento de suas figuras parentais e do seu próprio, o qual se caracteriza como o momento em que a mãe (ou uma figura materna) oferece a seu filho imagens que proveriam uma função de contorno, de proteção, relacionando-as a uma função materna de continente da organização do espaço psíquico ${ }^{2}$. Diz respeito a uma fase que poderíamos designar como sendo de antecipação subjetiva, de uma pré-formação egoica a que, sob a ótica de Jacques Lacan (1998a), psicanalista francês e leitor de Freud, refere o estágio do espelho ${ }^{3}$.

De acordo com Lacan (1998a, p. 100), o estágio do espelho designa "[...] um drama cujo impulso interno precipita-se da insuficiência para antecipação", oferecendo, ao sujeito enganado pela identificação a uma imagem, fantasias que passam de "[...] uma imagem despedaçada do corpo até uma forma de sua totalidade que chamaremos de ortopédica".

É dessa captura pelo olhar, segundo Lacan, torna-se possível à criança conquistar uma primeira noção sobre si mesma, a qual se presentifica sob a forma de uma imagem, que, embora precária, conferelhe sustentação até que a mesma se torne sujeito de linguagem. Por mais que nesse momento não tenha ela ainda conquistado o registro simbólico, a criança adquire ciência da sua independência do corpo materno - de modo superficial e imagético, como destacamos. Nesse sentido, quando essa fase é superada, ou melhor, quando o narcisismo primário é recalcado e o sujeito apresenta um eu formado de imagens que fizeram parte de sua constituição subjetiva, o duplo inverte seu aspecto, tornando-se estranho anunciador da morte, tal como já destacava Freud em seu ensaio sobre o estranho (Freud, 1969). Ou seja, com o recalque o duplo sofre uma inversão tópica, que, ao ser revelada ao sujeito, o faz experimentar uma espécie de morte subjetiva.

Como podemos perceber, essa ideia de Freud guarda semelhança com o entendimento lacaniano acerca do estranho, o qual postula que o estranho surge quando a falta ${ }^{4}$ assume uma imagem, porquanto de fato ela deva ser sem imagem. Isso pode parecer demasiadamente assombroso para o sujeito, além de estranho, pois sinalizaria sua morte subjetiva. É importante notar, ainda, que Lacan trata dessa temática do unheimlich freudiano quando também aborda o conceito de angústia no Seminário, livro 10 (Lacan, 2005). 
A angústia é, para Lacan (2005, p. 23), um afeto especial que possui uma relação íntima, de estrutura, com a constituição mesma do sujeito; concerne mais a uma perturbação que precisamente um sentimento, uma emoção. Se, para Freud, a angústia estaria ligada a uma perda de objeto intensamente investido, seja perda da mãe, no nascimento, seja perda do falo ${ }^{5}$, na fase fálica ${ }^{6}$, para Lacan, a angústia consistiria em uma perturbação que surge quando o sujeito é confrontado com o desejo do Outro, o qual não se ligaria a uma falta objetal, tal como seria tomada na teoria freudiana. Porém, a angústia não é sem objeto, ela tem relação ao falo ou equivalentes. Na visão lacaniana, ela surge quando algo aparece no lugar ocupado pela correspondência do objeto $a^{7}$, objeto causa do desejo, que é o equivalente metonímico do falo. Se esse objeto não demarcar uma falta, o sujeito é colocado diante de uma inquietante estranheza, angustiando-se. Assim, quando o lugar da falta não é assegurado ao sujeito, sua imagem especular se torna independente dele, tornando-se um duplo que lhe causa horror e angústia. Como nos lembra Chemama e Vandermersch (2007), é exatamente dessa forma que o sujeito vê-se dependente do Outro, ao ser invadido pelo objeto no lugar da falta, restando ao mesmo apenas a certeza assustadora que o tira do campo da simbolização.

Essa sentença permite, pois, compreender porque Lacan em seu seminário sobre a angústia defende a existência de uma relação fundamental entre essa e o desejo do Outro. Para ele, esse Outro é o lugar do significante ${ }^{8}$ para a definição de angústia, a qual ocorre na relação do campo do significante com o Imaginário ${ }^{9}$. Assim, a concepção desse afeto, na sua articulação entre Simbólico ${ }^{10}$ e Imaginário, não se separa, para Lacan, da representação, da produção de sentido. Ou seja, para falar de angústia, Lacan parte da própria definição de sujeito como determinado pelo significante, como constituído pelo traço unário ${ }^{11}$, o qual precede o sujeito. Na relação ao Outro, o sujeito se inscreve como resultado dessa marca significante. Mas há um resto, algo irracional e enigmático, ou seja, o objeto $a$, que comprova a alteridade do Outro (Lacan, 2005). Esse resto refere, por seu turno, um objeto que escapa à imagem especular, que escapa ao sujeito, e faz o sujeito se perguntar o que o Outro quer dele. Assim, a angústia adviria quando um mecanismo faria surgir alguma coisa unheimlich no lugar do objeto a, como imagem da falta, fazendo a falta faltar (Lacan, 2005).

O significante coloca um mundo ao sujeito, a partir do qual ele pode falar, e com isso, se enganar; fala pelo qual se pode percorrer o caminho que aproxima o sujeito daquilo que acredita ser o objeto de seu desejo, mas quanto mais ele se aproxima do objeto, maior é o que representa a imagem especular, e com isso, maior é seu engano (Lacan, 2005). A angústia é o corte, a porta de entrada do significante no sujeito, que determina seu funcionamento, o furo no Real ${ }^{12}$. E é precisamente este corte que se abre e que deixa aparecer o inesperado, a visita, a novidade, o estranho. A angústia sinaliza o Real, é o sinal que não engana, que aponta, para Lacan (2005) o resto do sujeito.

Educação \& Realidade, Porto Alegre, v. 38, n. 2, p. 501-520, abr./jun. 2013.

Disponível em: <http://www.ufrgs.br/edu_realidade> 
Um Entre o Outro e Eu

É importante destacar, a despeito das formulações lacanianas sobre angústia, que esta se diferencia estruturalmente do unheimlich, apesar das relações traçadas entre os dois conceitos. Além disso, tal distinção permite um entendimento maior sobre a constituição psíquica do sujeito. Para além do corte, do furo no Real, o resto do sujeito, sinalizado pela angústia, existe um mundo que, mesmo considerado externo para ele, é-lhe também próprio. É uma esfera exterior excluída no interior do sujeito.

A partir de Vieira (1999), que realiza uma leitura atenta do Seminário, livro 12, de Lacan, é possível compreender o ponto de intersecção e de diferenciação entre o unheimlich e a angústia. Para Vieira (2000), a angústia está muito além do estranho na medida em que se situa aquém da imagem do eu. Esta se estruturaria a partir da imagem do outro no reflexo especular, duma imagem capturada pelo olhar que faria emergir uma primeira ideia do eu. Já a angústia não teria causação, sendo seu objeto vazio, sem imagem, sinal da falta e motivo de desejo. Isso explica porque a distinção entre objeto a e i (a) revela o que é referente à angústia e o que é referente ao Unheimlich, respectivamente.

Vieira (2000) ainda aponta o lugar em que se situaria o estranho: um intervalo entre duas esferas, dois mundos, quais sejam: o psiquismo e a realidade interpretada por ele. Este espaço é o lugar da vacilação da imagem do eu, a qual deixa de ser fechada, total, na medida em que aponta, dá abertura para o infinito. A abertura para o infinito, a possibilidade de sua existência, insistência e incidência sobre o sujeito é o que gera um sentimento angustiante, próprio ao estranho.

$\mathrm{O}$ unheimlich acaba por denunciar, indicar a passagem entre um mundo fechado e o infinito por meio de uma imagem inquietante que abala as certezas narcísicas do sujeito; a angústia, em contrapartida, encontra-se mergulhada nessa infinidade suturada pelo eu e sua realidade, pelo eu e o duplo. Em sua emergência, a angústia reclama a reinstalação da alteridade.

Lacan nos ensina, ainda, que é possível dar visibilidade ao estranho, significá-lo. Assim, a angústia poderia ser aparentemente tomada como a sensação mesma de ser sujeito, afeto puro de sujeito, do momento de sua instalação. E é essa angústia, afetação pura, que deve surgir no advento do estranho, que se apresenta ao mesmo tempo familiar, como algo do suspiro primeiro, noção primeira do sujeito e impressão sensível primordial da marca do significante. O sujeito busca, contudo, se afastar da angústia, marca da incidência do Outro, (in)certeza que in(quieta), de forma a enganar em sua cadeia significante, a qual aponta a ele diversos caminhos, demandando do sujeito escolhas a serem feitas, firmando sua identidade, marcando diferença entre aquilo que é, aquilo que poderia ter sido e não é. $\mathrm{O}$ encontro do sujeito com o outro, seu igual, seu objeto, diz respeito ao encontro com aquilo que não é, com o que poderia ter sido, com o que seria ele mesmo se o sujeito não fosse constituído pelo corte que marca sua diferença e sua identidade. $\mathrm{O}$ 
encontro com o outro pode, assim, se dar de diversas formas, podendo suscitar a angústia, provocar estranhamento. O estranho trata, ao fim e ao cabo, do reconhecimento do estrangeiro que habita o Eu, um eu.

\section{Intermezzo: o estrangeiro de mim, outro}

A noção de estrangeiridade está intimamente relacionada com o estranho. Tal termo aduz ao encontro de um estranho no mesmo, isto é, ao reconhecimento do mesmo como sendo o estranho, o distante, o diverso, o singular. Esse sentimento é, por certo, um dentre alguns que nos tornam capazes de conviver com o outro. À noção de estrangeiridade se associa a da infindabilidade, em outras palavras, o caráter infindável, insondável, distante, desde sempre e para sempre distante do outro. Há um abismo que separa de modo invariável o mesmo do outro, uma síntese nem sempre possível. O sentimento do estranho aduz assim, a uma impossibilidade de capturar numa imagem plenamente identificável o outro; ele opera como algo refratário a um reconhecimento total, absoluto, é como se o outro, estranho ao mesmo, não pudesse ser controlado, definido, delimitado; já que depende do olhar do mesmo sobre o outro. É apenas a partir de si mesmo que o sujeito pode definir o outro, porquanto seja também definido pelo outro a partir do alcance de seu próprio olhar. As formas de relação do sujeito com o outro, e vice-versa, dependem dessa condição, ou seja, da incidência do Outro sobre o sujeito e do quanto este conseguiu se tornar independente, reconhecendo-O.

\section{A Representação do Estranho, Outro}

De um ponto de vista antropológico, uma sistematização mais clara sobre a representação do outro pode ser encontrada no livro $A$ Conquista da América, de Tzvetan Todorov (2010), o qual apresenta a descoberta e as relações que se estabelecem entre o eu e o outro a partir da chegada europeia nos territórios americanos. Todorov propõe a análise dessa chegada, e do que dela representou em relação ao encontro dos europeus com os índios, diferenciando quatro etapas: descobrir, conquistar, amar, conhecer.

No momento em que aborda a etapa do conhecer, Todorov (2010) menciona que a relação com o outro não acontece a partir de uma dimensão única, mas ocorre através de diversos modos que definem diversas tipologias, das quais ele distingue três eixos principais - e os quais trazem a questão da alteridade: o axiológico, no qual se realiza um julgamento de valor: o outro é bom ou é mau, apetece ou não apetece, é igual ou inferior ao referente (o mesmo, o eu, o mim); o plano praxiológico, que ocorre na ação de aproximação ou distanciamento, que define o eixo em que o referente adora os valores do outro, identificando-se com ele, assimilando-o, impondo a ele a imagem do referente; entre essa perspectiva de submeter-se ao outro ou submeter o outro ao referente existe ainda a possibilidade de permanecer neutro ou indiferente;

Educação \& Realidade, Porto Alegre, v. 38, n. 2, p. 501-520, abr./jun. 2013. 509

Disponível em: <http://www.ufrgs.br/edu_realidade> 
Um Entre o Outro e Eu

e em terceiro plano Todorov apresenta o epistêmico, segundo o qual se pode conhecer ou ignorar a identidade do outro. Ainda que esses planos possam coexistir e se relacionar, Todorov $(2010$, p. 270) afirma que eles são bem definidos, pois, é possível amar sem conhecer, conhecer sem se identificar e se identificar sem amar; diz ele: "[...] conquistar, amar e conhecer são comportamentos autônomos e, de certo modo, elementares".

Com efeito, os diferentes modos de reagir frente à presença do outro, representante do estranho, dependem de como o sujeito reconhece o Outro, como se coloca a ele a questão da alteridade. A relação do estranho com o outro pode ser realizada na medida em que o outro representa o estranho, provocando estranheza, suscitando a angústia.

Ao tomar a Psicanálise como sua matriz epistemológica, Saceanu (2005) reconhece a existência de vários modos de reação ao elemento estranho, descobrindo em sua pesquisa destinos da estranheza. A autora, embasada por Freud, ressalta o recobrimento por uma identidade, quando há uma tentativa de fixar uma imagem especular a fim de afastar a angústia decorrente do encontro com o estranho. Como um segundo destino do estranho, a autora aponta a emergência da angústia, em que o recobrimento por uma identidade falha e o sujeito é tomado por uma angústia paralisante. A agressividade dirigida ao estranho seria um terceiro destino, em que há hostilidade diante do elemento estranho; ao passo que um quarto destino diria respeito ao que a autora chama de “[...] possibilidade de abertura para o novo [...]" (Saceanu, 2005, p. 56).

Em relação a esses dois últimos destinos, Saceanu (2005) relata que para o ser humano a necessidade de aproximação é tão vital quanto a necessidade de afastamento, sendo que estão sempre presentes, ao mesmo tempo, a hostilidade e a necessária constituição de laços sociais entre os homens. Frente a isso, a autora (2005) acredita que existem hoje dois modos principais de relação com a alteridade: de um lado, existe a tentativa de fusão com o outro, não sendo reconhecida a sua diferença; e, por outro lado, a impossibilidade de identificação com o outro, de um sujeito que se depara com uma alteridade para o qual é apresentada uma diferença sobremaneira radical. Ela alerta, ainda, que esse distanciamento exacerbado é o que pode possibilitar a crueldade em todas as suas formas. Assim, nas duas formas atuais de reação ao outro não há o reconhecimento da alteridade.

Essa deficiência de reconhecimento do Outro na atualidade pode acontecer em decorrência do seguinte: na contemporaneidade, coexistem dois imperativos, o "seja igual" e o "seja diferente". Porém, pode-se afirmar que o "seja diferente" é um imperativo ilusório, pois significa uma exigência de ser original, de ser criativo, desde que se mantenha o mesmo, desde que sejam mantidas as regras do espetáculo. Ou seja, o ser diferente implica muito mais uma questão de imagem, de visibilidade voltada ao exterior, do que uma diferença propriamente subjetiva (Saceanu, 2005, p. 225). 
Assim, quando existe uma manifestação de agressividade em relação ao estranho que se impõe ao sujeito, a sua familiaridade não é reconhecida, pois, recalcada. No entendimento de Saceanu (2005), a crueldade perversa talvez possa ser caracterizada como a reação que hoje predomina nas relações sociais, pois observa nestas uma recusa em reconhecer a familiaridade do outro, do estranho, decorrente de uma profunda indiferença e irresponsabilidade por este outro, que pode ser representado por sujeitos ou grupos sociais que são considerados irrelevantes na contemporaneidade. Assim, em tal maneira de reagir ao estranho não haveria alteridade, não haveria reconhecimento do Outro. O não reconhecimento da alteridade se diferencia do ódio do outro, pois até mesmo por meio deste sentimento, um lugar pode ser atribuído a ele (Saceanu, 2005).

Considerando essa indiferença, o Outro possui hoje diversas faces, podendo estar em qualquer lugar. Porém, a autora (Saceanu, 2005) aponta que o principal critério de familiaridade, de pertencimento é a participação no consumismo. Ou seja, quem consome, é reconhecido, quem não consome, está fora. Aqueles que não fazem diferença no mercado de consumo são os radicalmente estranhos. Nesse caso em que o Outro é tão distante, com quem o sujeito não é capaz de qualquer identificação, ela aponta "[...] o Outro que morre de fome lá na África, que mora lá na favela, que pede esmolas na rua, etc” (Saceanu, 2005, p. 215).

Assim como a distância radical que pode levar à indiferença e à crueldade com relação ao outro, a aproximação absoluta também é mortífera, já que esse modo de relação que cola os sujeitos não permite espaço para o reconhecimento da alteridade. Ou seja, é fundamental a presença do igual, do mesmo, do próprio, mas a diferença é também vital ao sujeito, já que não há subjetivação possível sem abertura ao Outro, ao que vem de fora, à alteridade. Nessa perspectiva, a destruição do estranho implica no aniquilamento do que é próprio. Se for possível reconhecer essa crueldade, abrem-se caminhos alternativos que conduzam ao estranho sem que seja preciso destruí-lo. Isso explica porque para Saceanu (2005), para além da crueldade, existe no homem a hospitalidade. A autora acredita que a possibilidade de criação do novo através de uma experiência de estranhamento pode configurar um dos destinos do estranho, traduzindo-se na hospitalidade daquilo que surge estranhamente para o sujeito (Saceanu, 2005). Desse modo, o que Saceanu procura postular é que o estranhamento é um momento disruptivo que se abre para mudanças no imaginário do sujeito, e sendo assim, pode promover mudanças subjetivas. Ou seja, para além de uma espécie de angústia paralisante e da agressividade, podem advir novos significantes. E é justamente dessa forma que a autora mostra que a crença no desdobramento do estranho num aspecto positivo, mais familiar, conduz ao vislumbre de uma construção para além da experiência de estranhar (Saceanu, 2005).

Ao tomar a educação como sua baliza e, mais especificamente, a pedagogia, Carlos Skliar pretende, tal como Freud, Todorov e Saceanu,

Educação \& Realidade, Porto Alegre, v. 38, n. 2, p. 501-520, abr./jun. 2013.

Disponível em: <http://www.ufrgs.br/edu_realidade> 
Um Entre o Outro e Eu

discutir o estranho sob o ponto de vista relacional e representacional de uma alteridade radical, a fim de pensar, à contrapelo dos dois primeiros e em consonância com a última, uma pedagogia (improvável) da diferença. De acordo com Skliar (2003), o ato de representar envolve um olhar que vê o mundo de dentro pra fora, seguindo uma mesma direção. Com isso, o conceito de representação designa a representação do outro a partir do mesmo. O autor (Skliar, 2003) afirma que se a representação é uma trajetória que parte de um sujeito até o seu outro, esse outro se torna um objeto do anterior. Nessa perspectiva, a representação assume uma relação com o poder, a qual implica pensar em quem tem o direito de representar quem, e como o outro, grupos sociais e culturais são inscritos nos discursos e nas imagens sociais nessa atividade de representar.

Assim, fica implícita a ideia de que as pessoas, os objetos, os acontecimentos do mundo não carregam consigo um significado preestabelecido, sendo que a classificação última do mesmo e do outro estaria sempre num outro plano. A visibilidade ou invisibilidade do outro depende do olhar que este recebe, sendo que é o olhar do sujeito que é capaz de sentenciar quem ele mesmo é e quem são os outros (Skliar, 2003).

A análise de Skliar se refere, mais precisamente, ao sujeito deficiente, o anormal, o diferente, inscrito numa ordem educacional que $o$ aparta da normalidade, que o representa como estranho ao mesmo, ao igual. Tal afirmação deixa transparecer uma fronteira clara entre interioridade e exterioridade, sem implicação entre os dois termos. Para ele, $o$ ato de classificar já traz consigo mesmo o ato de excluir e incluir, e isso pode ocorrer em termos de produzir, representar, normalizar espacialidades, em representações de mapas que mostram o que está dentro e o que está fora.

A definição de uma espacialidade como espaço único de inclusão e exclusão é, como bem observa Skliar (2003), um ato perverso, na medida em que se insiste na reprodução do outro como o mesmo, na medida em que existe rejeição dos não espaços, das fronteiras, dos espaços outros. Skliar pretende da mesma forma que Saceanu, tornar o espaço determinado por um comum mais permeável a suas bordas, aos entres, ao que não é propriamente comum, mas outro, distinto, diferente. As premissas de ambos os autores nos permitem pensar sobre o estatuto crítico e reflexivo do estranho antes como forma de dinamitar a certeza do que meio para a resolução ou a dissolução da tensão entre o eu e o outro.

\section{A Arte de Estranhar e se Estranhar - distanciar para aproximar}

Há, certamente, no âmbito da educação uma série de tentativas de equacionamento dessas forças que se interpõem no convívio social. Uma dentre inúmeras intuições pedagógicas sobre o estranho, a qual te- 
ria em vista uma proposta crítica de ensino e aprendizagem é extraída da arte. Uma das iniciativas mais conhecidas talvez seja a de Bertold Brecht, célebre pedagogo do teatro. Ainda que Brecht não tenha se debruçado sobre a questão do estranho, ao menos não de forma tão categórica quanto os autores que arrolamos neste estudo, é a partir da sua ideia de efeito de alienação ou distanciamento que se pode aqui correlacionar tais noções. Brecht menciona que o seu efeito de distanciamento consistia em tomar algo do contexto familiar, comum, de fácil acesso para passá-lo para o peculiar e inesperado. Como destaca Royle (2003), o interesse de Brecht está em torno das possibilidades políticas e revolucionárias embutidas na transformação do familiar em estranho.

O estranhamento ou distanciamento, segundo Gerd Bornheim (1992), um importante estudioso de Brecht, designa um conceito que vai além do teatro, levando-se em conta a necessidade de um terceiro elemento para que se possa vislumbrar àquilo que nomeamos como sendo o duplo. Um exemplo trazido por Bornheim é o de um homem que só consegue ver a mãe como mulher de outro quando no lugar de seu pai ele tiver um padrasto, estabelecendo, assim, o distanciamento. Com o distanciamento, Brecht pretendia eliminar as emoções de terror e piedade - postuladas por Aristóteles como sendo as emoções adequadas à Tragédia Clássica; Brecht supunha que tais emoções eram para o espectador, devendo, em contrapartida, serem substituídas pela curiosidade e admiração, as quais reduplicam o distanciamento do espectador, visto que este atingiria uma dimensão em que ele próprio se vê vendo o espetáculo. Podemos afirmar, nesse sentido, que a experiência de se ver vendo algo, de se flagrar imerso em algum evento, é um fenômeno que conduz inevitavelmente ao estranho. Para Bornheim (1992), esses dois tipos de representação, a identificação - pela via aristotélica - e o distanciamento - pela via brechtiana distinguem-se qualitativamente, pois, à diferença de Aristóteles, Brecht pretende filtrar a ilusão teatral, tornar o espectador um agente que catalisa a emoção e não um ente sobre o qual essa age. Brecht quer capturar a emoção proveniente do estranhamento como uma forma de tomada de consciência.

De acordo com Bornheim (1992), foi em 1936 que Brecht promulgou sua teoria sobre o estranhamento ou distanciamento. Tal afeto foi buscado por Brecht no seu teatro épico, forma de encenação que supõe ser o espetáculo algo sóbrio, o qual deveria trabalhar os conteúdos de forma objetiva e racional. Tal notação aproxima o teatro épico à ciência, apelando à razão do espectador, mas sem excluir a possibilidade do sentimento. Brecht pretendia que o espectador fosse um agente transformador na sociedade. O que Brecht propunha com o seu teatro era desnaturalizar o pensar, o perceber, separar o dentro do fora e vice-versa. Para Brecht, como salienta Bornheim (1992), fazia-se necessário olhar o olhar, visto que o mundo se torna o reino em que comumente impera o mesmo.

Educação \& Realidade, Porto Alegre, v. 38, n. 2, p. 501-520, abr./jun. 2013. 
Um Entre o Outro e Eu

Tais afirmações permitem estabelecer um nexo temático e funcional com aquilo que Skliar (2003) denomina, desde um registro educacional, a necessidade de ampliação de uma imagem supostamente fixa do mundo, caracterizado por antagonismos; para tanto, é preciso agregar outras imagens, as quais sempre estiveram presentes, mas que não recebiam atenção do nosso olhar - moldado por uma lente histórico cultural que tornava essas mesmas imagens invisíveis.

Com efeito, é com essa faculdade de dispor o olhar para o que está à frente, voltar o olhar para o que estava invisível, que Skliar propõe que seja vista a Educação. Skliar (2003) denuncia que ao invés de questionar a educação, a pesquisa neste âmbito tende a mudá-la, porém, tais mudanças são camufladas de mesmidade, trocando-se apenas os nomes. O que ocorre, diz ele (Skliar, 2003, p. 197) com as mudanças educativas é que elas "[...] nos olham agora com esse rosto que vai despedaçandose de tanta maquiagem sobre maquiagem. Porque as mudanças nos olham, e ao olhar-nos encontram só a metástase de leis, de textos, de currículos, de didáticas e de dinâmicas".

Frente a esse rosto maquiado e que se insiste em maquiar, Skliar busca retomar a origem, como a educação se tornou essa transformação e essa reforma incessante que perdeu seu ponto de partida, e com isso ele retoma a Modernidade e o advento da instituição educativa que surgiu com ela, a escola. $\mathrm{O}$ autor aponta ainda que o tempo e o espaço da modernidade e da escolarização são aqueles que buscam a ordem, a classificação, as mesmidades homogêneas, sem qualquer influência do outro (Skliar, 2003). E com isso, a escola tende a igualar os sujeitos, a reduzi-los, a integrá-los, sendo que não pode conceder espaço para o mesmo e para o outro em um só tempo. Mas assim como o projeto da modernidade se tornou impossível, a escola também foi se fragmentando, até chegar à atual escola da perplexidade.

\section{Uma Pedagogia Estranha, Antipedagógica, Antipedagogizante}

A palavra pedagogia designa etimologicamente a condução da criança. Na Grécia Antiga, quem realizava tal função era um escravo, o pedagogo, cuja significação etimológica refere aquele que conduz. Dessa maneira, em seus princípios, tal papel incumbido ao escravo era tomado em seu sentido literal, já que a função do pedagogo era absolutamente impessoal, restrita ao acompanhamento das crianças até o paedagogium, lugar em que as mesmas recebiam seus ensinamentos.

A falta de envolvimento e a irrelevância dos primeiros pedagogos com a educação das crianças pode eventualmente nos surpreender, nos incomodar, visto que a noção hoje cristalizada de pedagogia e pedagogo lhe é consideravelmente inversa. Contudo, deixemos que este sentido-outro da pedagogia nos inquiete e nos provoque questionamentos acerca da relação desta significação primeira, estranha, com a noção da prática pedagógica atual, familiar. 
Podemos facilmente tender a atribuir à pedagogia a base da educação de um sujeito, sendo que a responsabilização pelo outro (independentemente da forma como este se configure, de onde ele venha, quem ele seja) seja total, incondicional. À pedagogia coube, nesse sentido, a tarefa de reconhecer no sujeito em formação o outro, de introduzilo, de braços abertos, à nossa cultura.

A integração e a adaptação de um indivíduo a uma cultura é o projeto civilizatório de conquista da felicidade, de modo que a aderência do sujeito a uma comunidade constitui-se como uma atividade altruísta. Todavia, ela não se dá de maneira tão harmônica quanto se poderia pensar, sobretudo porque a necessidade de satisfação individual pode se chocar com as necessidades de uma dada coletividade. Dito de outro modo, desejamos a nossa própria satisfação, e, de maneira ilusória, a buscamos com o outro. Isso é o que aponta Freud (2010), quando afirma que a cultura tende a supor que o indivíduo pode controlar seus impulsos instintuais e viver em prol de um bem comum. Para exemplificar, Freud (2010) afirma que a educação acaba por negar as manifestações de sexualidade, de agressividade, autodestrutivas, dando a entender ao educando que todos, seus iguais, os outros, cumprem as exigências sociais e são felizes assim, de modo que a realização pessoal dentro da cultura se torna uma exigência, e seu alcance, uma ilusão.

Nessa perspectiva, Rodrigues (2007) aponta que, em vez de abertura ao outro, em vez de encontro de sujeitos, o que ocorre num ambiente educativo é, de acordo com sua experiência como educador, um desencontro de sujeitos. Para Rodrigues (2007), esse desencontro é traduzido na incompreensão de um outro que não se encaixa nos parâmetros educacionais, fato que leva à busca de novas pedagogias para promover o seu enquadramento nas normas da escola. Dessa forma, a adoção dessa postura, de encarar os desencontros como problemas pedagógicos concernentes à adaptação ao ambiente escolar apresenta-se como um mecanismo de defesa contra o desespero do não saber, do não conhecer aquilo que é tomado como verdadeiro sobre o sujeito.

Com isso, Rodrigues (2007), adotando a ideia do sujeito do inconsciente da Psicanálise, aponta que não sabemos nada sobre ser sujeito, esse que se constrói nas relações primordiais estabelecidas com as primeiras figuras. Somos alheios a nós mesmos e ao que nos acontece, e por isso que o estabelecimento de regras e teorias pedagógicas no campo da educação pode vir a suprir a angústia do desconhecido, do não saber ser sujeito. Nesse sentido, a infinidade de teorias e metodologias que acercam o ensino e a aprendizagem, as quais se interpõem sobre o outro, intermediando a relação entre os sujeitos da educação, tanto mascaram a dificuldade de reconhecer o sujeito que é o outro, quanto dificultam o encontro efetivo e afetivo do eu com o outro.

Porém, o autor aponta a insistência e a resistência pedagógica na busca por orientações e condições dessa ordem que conduzam à efetiva relação educativa, reforçando a ilusão de encontro com o outro. É ape- 
Um Entre o Outro e Eu

nas o reconhecimento de tal situação de desencontro nas relações entre os atores da educação que pode, então, oferecer condições para um possível encontro entre eles. Como lembra Saceanu (2005), é possível que ocorra abertura ao novo; nesse sentido, é para além da angústia e da agressividade que podem advir novos significantes. Isso explica porque o estranho pode se desdobrar num aspecto positivo, mais familiar, conduzindo ao vislumbre de uma construção que se estira para além da experiência do estranhar.

No entanto, para que se consiga promover esse encontro com o outro é preciso que haja, primeiro, um retorno do sujeito a si mesmo, o qual deve buscar compreender-se como sujeito. Assim, Rodrigues (2007) sugere que o primeiro outro a ser encontrado na tarefa do reconhecimento é o eu mesmo. Contudo, tal tarefa é desesperadora, e se intensifica no campo da educação, visto que é o lugar por excelência do escamoteamento do vazio que nos constitui e que constitui nossas regras, normas de conduta e projeto civilizatório.

Um retorno ao outro que constitui o sujeito como si mesmo conduz, como vimos, a uma estranha experiência: a de ver-se como outro, alienado no Outro, de perceber que seus desejos e escolhas são em certa medida dependentes de uma ordem alheia. Obviamente, tal reflexão encontra resistência, sobretudo porque o sujeito não tende a olhar dessa maneira sobre si mesmo, visto que tal atividade constituiria ou mesmo demandaria uma espécie de destituição narcísica. Em relação a isso, Freud (2010) aponta que o engodo, que a ilusão e que o mal-estar passados pela educação poderiam ser consideravelmente reduzidos, se o sujeito conseguisse reconhecer a diferença entre o que o que gostaria de ser e o que ele é de fato.

De acordo com Rodrigues (2007), o não olhar para si mesmo do sujeito implica a negação do outro, que acaba sendo tomado como objeto que esse deseja manter como ilusão, não o reconhecendo também como sujeito. Na medida em que o sujeito consegue voltar o olhar para si mesmo pelo outro, de forma a tomar o não enquadramento do outro não como um desajustamento social ou como uma incapacidade simbólica vinda de sua própria condição subjetiva, como sendo falha e insuficiência do simbólico que forma e institui nossa cultura, é possível fazer com que as tentativas de mascaramento daquilo que surge como excedente, daquilo que não se pode lidar ou mesmo simbolizar, cedam lugar ao que condiz realmente com a impossibilidade simbólica, a angústia, a qual pode surgir a partir da percepção do estranho, do que só pode ser sentido fielmente como tal.

Nesse sentido, o caminho da educação não estaria a priori, de antemão, traçado. Uma pedagogia antipedagogizante levaria em consideração a condição do não saber, a qual procura voltar o olhar para o si mesmo, tomando-o como outro, pedagogia que desconfia de metodologias já constituídas, que está disposta a abrir-se ao novo, o estranho visto com proximidade e familiaridade. 
Nabuco (2010), por seu turno, propõe que ao invés de pensarmos e de praticarmos uma educação repressiva; precisamos realizar uma educação inventiva e da criação, já que, na era da globalização, a norma e a repressão perdem seu lugar para a fluidez e para o gozo das relações sociais. Contudo, desde que seja mantida a ética como referência, as práticas educativas podem ser reinventadas. É trilhando esse caminho, o da ética, que se faz possível a produção dos laços sociais e esse parece ser precisamente o grande desafio da educação contemporânea. Com isso, o ensino que já está pronto, cumprido, pode ser desestabilizado, balançado com a ideia de um ensino ainda não pronto, ainda não formulado, não concluído, prestes a se realizar no aqui e agora, convocando e colocando os atores da educação no lugar do desconhecido pronto a ser reconhecido. Um lugar de não saber que forma um saber - consciente de seus limites e de suas imprecisões, consciente de sua estranheza.

Recebido em 31 de outubro de 2012 Aprovado em 26 de abril de 2013

\section{Notas}

1 Outro: Conceito que designa o lugar anterior e exterior ao sujeito, que o determina. Pode ser ocupado pelo lugar e função materna e paterna na elaboração das instâncias psíquicas do sujeito. Porém, essa é uma primeira dimensão da alteridade reconhecida pelo sujeito, a qual, com o tempo, pode se assemelhar a ele como outro. O Outro, ou o Grande Outro, é a Alteridade que permanece para além das representações e identificações imaginárias proporcionadas pela relação com o pequeno outro, sendo assim uma dimensão radicalmente anterior e exterior, à qual o sujeito se sujeita. Essa dimensão pode ser confundida com a própria ordem da linguagem (Chemama; Vandermersch, 2007, p. 282-283).

$2 \mathrm{O}$ narcisismo primário que representou para o sujeito a sua proteção - e que designa o amor por si mesmo - pode ao mesmo tempo ser algo seguro ou assustador para o sujeito, dependendo das condições de superação dessa fase. Se não existe confronto com a diferença, vislumbre da ausência fálica na mãe, é muito mais confortável para o sujeito apenas reproduzir o mesmo, como se tudo o que fizesse parte da sua vida fosse algo originado dele mesmo, que ele ama por fazer parte dele. Porém, como ressalta Weber (1973), referendado por Freud, a castração instala no sujeito a condição de acesso à diferença, mudando a lógica da duplicação do narcisismo primário, para a lógica do desejo que tende ao infinito, permitindo ao sujeito o reconhecimento do outro.

$3 \mathrm{O}$ tradutor de O Estágio do Espelho como Formador da Função do Eu, texto que aparece nos Escritos, deixa claro que este Eu é o Je e não o moi. Portanto, a não indistinção entre imaginário e simbólico, o estágio do espelho é um momento da formação do sujeito do inconsciente, o Je, que manifesta antecipadamente a matriz simbólica sob a forma de [eu], antes de entrar no jogo de identificação com o outro e de encontrar-se como sujeito de linguagem (Lacan, 1998a).

4 A falta é uma condição do ser falante, condição de ser sujeito, que atribui a ele uma incompletude geralmente despercebida, tanto nas imagens que enganam o desejo do sujeito, tanto nos conjuntos em que se conta. A falta 
pode ocorrer em três registros diferentes. Na castração, a falta é simbólica, de um objeto imaginário (falo materno). Na frustração, experimenta-se uma falta imaginária de um objeto real (seio). Para Lacan (1995), esse é o momento central da constituição da falta, em que a relação da criança com o objeto é direta e necessita de um agente, a mãe, para introduzir a presença-ausência do objeto. A sua presença e sua ausência ocorrem por meio do apelo da criança à mãe. Quando esta não responde mais, saindo dessa estruturação, a mãe se torna potência, real, é ela quem tem o poder, e à criança resta levar o objeto ao nível simbólico. Assim, na privação, a falta é real e o objeto é simbólico (falo, que funciona como significante), e é exatamente aí que o sujeito sente a falta mesma de ser. (Lacan, 1995, p. 59-70). Nessa medida, se a falta termina por ser real, a imagem que surgir dela será também real, e talvez por isso o estranho que surge no lugar da falta, como sua imagem, é assombroso.

5 Na Psicanálise, esse símbolo designa um significante e seus efeitos sobre um sujeito, em especial, a entrada da sexualidade na linguagem. O falo na cadeia significante de um sujeito revela a assunção de seu sexo e a inauguração de seu desejo (Chemama; Vandermersch, 2007, p. 141).

6 Fase designada por Freud que faz parte da organização psicossexual. A fase fálica é marcada pela angústia de castração, devido à proibição do incesto que interdita a criança na sua passagem pelo complexo de Édipo. Nessa fase, existe uma concentração das pulsões parciais sobre o órgão genital, tanto na menina quanto no menino, e a questão mais importante que a criança deve resolver é se tem ou não tem o falo. Quando a resolução ocorrer, a criança sai da fase fálica, o falo entra para a cadeia significante, definindo para o sujeito a significação de sua sexualidade (Chemama; Vandermersch, 2007, p.148).

7 Objeto a: conceito lacaniano para designar o objeto causa do desejo. Não é um objeto do mundo, mas é relativo a quatro partes do corpo: seio, fezes, voz, olhar. O objeto a é constituído num lugar além da necessidade, um lugar de demanda, tornando-se muito mais precioso ao sujeito do que a satisfação de condições de sobrevivência. O objeto a é emblemático; cria um campo ilusório, nem interior e nem exterior ao sujeito, que pode fazê-lo ligar-se a qualquer objeto. Ele é o ponto de intersecção entre os registros Real, Simbólico e Imaginário (Chemama; Vandermersch, 2007, p. 278-279).

8 Significante: elemento de linguagem que representa e determina o sujeito, que tem função para o sujeito não pelo seu significado, mas pela sua significância, pela imagem acústica que produz, podendo assim possuir muitos sentidos (Chemama; Vandermersch, 2007, p. 346-347).

9 Imaginário: registro subjetivo do eu procedente da constituição da imagem do corpo. É a partir do registro imaginário que se promovem as identificações e os engodos. Para pensá-lo, evoca-se sua relação ao Real e ao registro do simbólico (Chemama; Vandermersch, 2007, p. 198-196).

10 Simbólico: função que faz o homem ser um ser falante, a qual comporta partes conscientes e inconscientes que regem a linguagem e em especial o significante, determinando seus vínculos sociais e suas escolhas sexuais. O simbólico designa aquilo que faz falta ou que foi perdido, inscrevendo-se na experiência humana por meio de perdas as quais exigem uma integração, uma estrutura simbólica. A falta deixada por um objeto perdido é assim simbolizada por um significante, deixando um marco permanente em palavra e eternizando o desejo (Chemama; Vandermersch, 2007, p. 348-349). 
11 O traço unário promove e demarca, como explica Lacan (1998c, p. 135) no livro 11 de O Seminário, o ponto de identificação e diferença dos significantes de uma cadeia. Trata-se, em suma, de uma identificação a um traço único através do qual o sujeito pode se reconhecer e se diferenciar dos demais. É um referencial simbólico que sustenta a identificação imaginária.

12 Chemama e Vandermersch (2007, p. 325-326) conceituam o Real como a estrutura subjetiva que se define apenas em sua relação ao Imaginário e ao Simbólico. Relacionam-no ao impossível, àquilo que não pode ser falado ou escrito satisfatoriamente, àquilo que não pode cessar de não ser escrito. A intervenção simbólica expulsa o Real da realidade, recobrindo-o e, ao mesmo tempo, situando-o, instalando o lugar Real que "[...] já estava lá [...]" (Chemama; Vandermersch, 2007, p. 326). Assim, o sujeito não consegue nunca encontrar o lugar do campo Real na realidade, pois é inapreensível ao Simbólico, "a não ser sob a forma de um encontro que desperta o sujeito de seu estado ordinário" (Chemama; Vandermersch, 2007, p. 325).

\section{Referências}

BORNHEIM, Gerd. Brecht: a estética do teatro. São Paulo: Editora Graal, 1992.

CHEMAMA, Roland; VANDERMERSCH, Bernard. Dicionário de Psicanálise. São Leopoldo: Editora Unisinos, 2007.

FREUD, Sigmund. O Estranho. In: FREUD, Sigmund. Edição Standard Brasileira das Obras Completas de Sigmund Freud. Rio de Janeiro: Imago, 1969. Volume 17.

FREUD, Sigmund. O Mal Estar na Civilização. São Paulo: Companhia das Letras, 2010.

LACAN, Jacques. O Seminário: livro 4: a relação de objeto. Rio de Janeiro: Jorge Zahar, 1995.

LACAN, Jacques. O Estágio do Espelho como Formador da Função do [Eu] Tal Como Nos É Revelada na Experiência Psicanalítica. In: LACAN, Jacques. Escritos. Rio de Janeiro: Jorge Zahar Editor, 1998a.

LACAN, Jacques. O Seminário: livro 7: a ética da Psicanálise. Rio de Janeiro: Jorge Zahar, 1998b.

LACAN, Jacques. O Seminário: livro 11: os quatro conceitos fundamentais da psicanálise. Rio de Janeiro: Jorge Zahar, 1998c.

LACAN, Jacques. O Seminário: livro 6: o desejo e sua interpretação. Porto Alegre: APPOA, 2002.

LACAN, Jacques. O Seminário: livro 10: a angústia. Rio de Janeiro: Jorge Zahar, 2005.

MARTINI, André de; JUNIOR, Nelson Ernesto Coelho. Novas Notas sobre O Estranho. Tempo Psicanalítico, Rio de Janeiro, v. 42, n. 2, p. 371-402, 2010.

NABUCO, Maria Eugênia. Práticas Institucionais e Inclusão Escolar. Cadernos de Pesquisa, São Paulo, v. 40, n. 139, p. 63-74, jan./abr. 2010.

PEREIRA, Lúcia Serrano. O Estranho. Correio da APPOA, Porto Alegre, n. 157, maio 2007.

PORTUGAL, Ana Maria. O Vidro da Palavra: do estranho, literatura e psicanálise. Belo Horizonte: Editora Autêntica, 2012.

RANK, Otto. El Doble. Buenos Aires: Ed. Orion, 1976.

Educação \& Realidade, Porto Alegre, v. 38, n. 2, p. 501-520, abr./jun. 2013. 
RODRIGUES, Rogério. A Prática Educativa como uma Atividade de Desencontro de Sujeitos. Educação e Pesquisa, São Paulo, v. 33, n. 3, p. 445-458, set./dez. 2007. ROYLE, Nicholas. The Uncanny. Manchester; Manchester University Press, 2003.

SACEANU, Patrícia. A Inquietante Estranheza na Contemporaneidade. 2005. Tese (Doutorado em Teoria Psicanalítica) - Programa de Pós-Graduação em Teoria Psicanalítica, Instituto/Faculdade de Psicologia, Universidade Federal do Rio de Janeiro, Rio de Janeiro, 2005.

SKLIAR, Carlos. Pedagogia (Improvável) da Diferença: e se o outro não estivesse aí? Rio de Janeiro: Editora DP\&A, 2003.

TODOROV, Tzvetan. A Conquista da América: a questão do outro. Rio de Janeiro: Martins Fontes, 2010.

VIEIRA, Marcus A. A Inquietante Estranheza: do fenômeno à estrutura. Latusa, Rio de Janeiro, n. 4/5, p. 123-138, 2000.

WEBER, Samuel. The Sideshow, or: Remarks on a Canny Moment. Modern Language Notes (MLN), Baltimore, v. 88, n. 6, p. 1102-1133, dez. 1973.

Ana Paula Bellochio Thones é psicóloga; especialista em clínica psicanalítica; graduanda em Artes Cênicas, UFSM. Mestre do Programa de Pós-graduação em Educação da UFSM, Santa Maria/Rio Grande do Sul. Membro do FLOEMA - núcleo de estudos em estética e educação.

E-mail: anabellochio@yahoo.com.br

Marcelo de Andrade Pereira é doutor em educação. É professor adjunto do Departamento de Fundamentos da Educação da UFSM; é professor do Programa de Pós-Graduação em Educação da UFSM, Santa Maria/Rio Grande do Sul. É coordenador do FLOEMA - núcleo de estudos em estética e educação.

E-mail: doutorfungo@gmail.com 